\title{
Quando professores que ensinam matemática estão em atividades de pesquisa
}

\section{When are teachers who teach mathematics in research activities}

Maria do Carmo de Sousa ${ }^{1}$

\begin{abstract}
Resumo: A partir de investigação de cunho participante e longitudinal envolvendo licenciandos e professores que ensinam matemática na Educação Básica, tem-se como objetivo, neste artigo, apresentar alguns conhecimentos sobre o ensino de matemática que estão sendo explicitados nas pesquisas dos professores produzidas nos âmbitos do Mestrado (Profissional e Acadêmico) e do Observatório da Educação, as quais se fundamentam na perspectiva da Atividade Orientadora de Ensino (AOE). São consideradas sistemáticas e intencionais, conforme apontam os estudos de Cochran-Smith e Lytle, uma vez que consideram a dinâmica fluente das aulas de matemática, bem como, as particularidades e singularidades das salas de aula. São intencionais porque os professores, estudam, planejam ações e elaboram produtos educacionais que pretendem intervir, positivamente, nos processos de ensino e de aprendizagem de suas turmas. São sistemáticas porque sistematizam, de forma acadêmica, as intervenções que ocorrem nas aulas de matemática.

Palavras-chave: Ensino de matemática. Ensino Superior. Pós-graduação. Atividade de pesquisa. Formação de professores. Desenvolvimento profissional.

Abstract: This research is from research participant perspective and is longitudinal in nature involving undergraduates and teachers who teach mathematics in basic education. They have some knowledge about the teaching of mathematics that are being explained in surveys of teachers that are produced in areas of the Master (Professional and Academic) and Education Observatory. The completed surveys mostly are based on the theme of Guiding Activity of Teaching. The teacher is considered systematic and intentional, as Cochran-Smith e Lytle indicate, since they consider the dynamics of fluent math classes, as well as the particularities and peculiarities of the classrooms. Teachers are intentional, study, plan actions and prepare educational products that aim to positively intervene in the processes of teaching and learning in their classes. They are systematic and so academic interventions that occur in mathematics lessons are systematized.
\end{abstract}

Keywords: Mathematics teaching. Higher education. Post graduation. Research activity. Teacher formation. Professional development.

\footnotetext{
${ }^{1}$ Centro de Educação e Ciências Humanas, Departamento de Metodologia de Ensino, Universidade Federal de São Carlos (UFScar), Rodovia Washington Luís, km 235, CEP 13565-905, São Carlos, SP, Brasil. E-mail: $<$ mdcsousa@gmail.com>
} 


\section{Introdução}

Ao fazerem “um breve histórico do movimento dos educadores-pesquisadores", DinizPereira e Zeichner (2011, p. 13) afirmam que esse movimento já tem algum tempo, uma vez que "foi iniciado no final do século XIX e início do século XX". No entanto, no Brasil, apesar de Freire ter criado um modelo de pesquisa-ação, no final dos anos 1960 e início dos anos 1970 (DINIZ-PEREIRA; ZEICHNER, 2011, p. 15), é a partir dos anos 1990 que se percebem certas intenções, manifestas em algumas políticas públicas, no sentido de se valorizarem as reflexões, o fazer e o sentir dos professores da Educação Básica, enquanto se desenvolvem profissionalmente.

Apesar disso, ao analisarmos as políticas de formação de professores, poderemos inferir que, a maioria delas ainda está centrada na ideia de que tanto os professores da Educação Básica quanto os licenciandos são incapazes de pensar e, consequentemente, produzir conhecimentos sobre os processos de ensino e de aprendizagem que ocorrem nas salas de aulas, especialmente aqueles relacionados à matemática.

Constantemente, professores da Educação Básica que já lecionam são surpreendidos com ações, muitas vezes, impositivas, que ignoram seus conhecimentos, no que diz respeito: a como crianças e jovens aprendem matemática; ao currículo; aos materiais didáticos que podem auxiliar no ensino de matemática; à elaboração de produtos educacionais feitos por eles etc. Há grandes preocupações, tanto das universidades quanto dos órgãos públicos, única e exclusivamente, com o conteúdo matemático a ser ensinado. Logo, os professores são incentivados a conhecer, cada vez mais, os conteúdos matemáticos para que possam ensinar mais e melhor. Prioriza-se, aqui, o conhecimento para o ensino de matemática que é pensado por especialistas que, muitas vezes, não conhecem a realidade da Educação Básica. Aqui, tem-se como pressuposto que, quanto mais conteúdo matemático o professor souber, melhor será o ensino de matemática.

Em muitos casos, como, por exemplo, nas escolas particulares e, atualmente, nas escolas estaduais do estado de São Paulo, as aulas de matemática são entregues, aos professores, praticamente prontas, e são disponibilizadas tanto em apostilas quanto nos cadernos de professores e de estudantes. Cabe aos profissionais do ensino apenas utilizar os materiais que recebem, embora os elaboradores destes materiais afirmem, veementemente, que os professores são autônomos para utilizá-los, porque cabe a eles faz̧er bom uso dos materiais disponibilizados. Aqui, os professores da Educação Básica - a exemplo do que vem ocorrendo há décadas, durante as reformas educacionais, dentre elas, o Movimento da Matemática Moderna - continuam a exercer o papel de executores de currículos pensados e produzidos por especialistas (SOUSA, 1999). No caso específico do estado de São Paulo, desde 2008, as escolas recebem da Secretaria da Educação, bimestralmente, cadernos que são compostos por quatro situações de aprendiragem, ao mesmo tempo, recebem livros didáticos do governo federal que fazem parte do Programa Nacional do Livro Didático (PNLD).

A partir desta perspectiva de professores como executores, para que possam se inteirar das propostas apresentadas nos documentos oficiais e, consequentemente, nos livros didáticos, praticamente em todo o Brasil, vez ou outra, as Secretarias da Educação, oferecem cursos de curta duração, com, no mínimo, trinta horas, coordenados por especialistas da universidade. É muito raro ocorrer o contrário, ou seja, o professor ministrar cursos de curta duração para os especialistas das universidades e elaboradores de livros e materiais didáticos para que eles possam conhecer a realidade das escolas brasileiras. É como se os professores da Educação Básica não produzissem conhecimentos sobre o ensino de matemática que ministram. 
Entretanto, apesar das Secretarias de Educação investirem grandes cifras neste tipo de formação continuada, no documento "Estatísticas dos Professores do Brasil", elaborado pelo Instituto Nacional de Estudos e Pesquisas Educacionais Anísio Teixeira (2003, p. 39-40), encontra-se a seguinte afirmação: “[...] os cursos de formação continuada [...], aparentemente apresentam pouco impacto no desempenho dos alunos, e isto significa que mudanças sensíveis devem ser feitas nesta área, pois, [...] boa parte dos professores participa desses cursos".

Entendemos que, para haver mudanças sensiveis na formação continuada de professores e, consequentemente, no ensino de matemática, mais do que investir em cursos de curta duração, é importante a criação de políticas públicas que invistam na pessoa do professor, de forma que ele possa desenvolver atividades de pesquisa, que possibilitem com que suas preocupações se configurem em perguntas de pesquisa, de forma que possam conduzir suas práticas de sala de aula e auxiliá-lo a planejar suas ações, bem como a selecionar os materiais didáticos e as metodologias de ensino mais apropriadas para as suas salas de aula.

Assim, concordamos com Cochran-Smith e Lytle (2002, p. 79), ao considerarem que as pesquisas de professores podem nos auxiliar a construir "uma teoria diferente do conhecimento para o ensino", uma vez que as pesquisas dos professores podem ser entendidas "como uma forma diferencial e importante de conhecimento sobre o ensino". As autoras afirmam ainda que:

[...] a investigação feita pelos professores é uma forma de construir conhecimento tanto local quanto público; para os professores individuais; para as comunidades de professores; para os pesquisadores universitários; os formadores de professores; os políticos e os administradores da Educação. (COCHRAN-SMITH; LYTLE, 2002, p. 102)

É com este objetivo - o de apresentar alguns conhecimentos sobre o ensino de matemática, produzidos por professores da Educação Básica que ensinam matemática, enquanto estiveram envolvidos em atividades de pesquisa, no período de 2009 a 2012, no âmbito do Programa Observatório da Educação (OBEDUC), financiado pela Coordenação de Aperfeiçoamento de Pessoal de Nível Superior (Capes) - que escrevemos este artigo. Tais atividades estão sintetizadas em dissertações de mestrado, e, ao analisá-las a partir de categorias analíticodescritivas, fundamentadas nos estudos de Cochran-Smith e Lytle (2002), pudemos compreender melhor as preocupações destes professores, bem como suas escolhas teóricas e metodológicas que conduziram suas práticas naquele período.

\section{A atividade de pesquisa na formação dos professores da Educação Básica}

Segundo autores como Zeichner (1993) e Nóvoa (1992), para que o professor se desenvolva, seja como professor reflexivo seja como profissional da prática docente (PERRENOUD, 1993), seja como o investigador de sua prática (RIBEIRO, 1993), é fundamental que ele se mantenha no movimento da mútua recriação da teoria na prática e da prática na teoria. Nessa perspectiva, faz-se necessário definir o que elegemos como unidade desse movimento: a atividade de pesquisa. 
Aqui, consideramos o conceito de atividade como movimento de abstrair o resultado de ações, antes mesmo de realizá-las, provocadas por necessidades reais, advindas da interação do homem com o meio, pela condição de nele viver (MOURA et al., 2003).

Nesse sentido, a atividade será considerada atividade de pesquisa quando for capaz de definir os elementos constitutivos que permeiam o pensar sobre as elaborações decorrentes da análise das atividades orientadoras de ensino, feita pelos professores, ou, ainda, quando permitir a análise dos inesperados (CARAÇA, 1998), caso estes surjam durante o processo de formar-se pelo conhecimento científico.

A atividade de pesquisa é peça fundamental para a formação de professores e, por este motivo, vem sendo defendida por diversos autores, há vários anos.

Segundo Diniz-Pereira e Zeichner (2011, p. 11, grifo dos autores): “[...] diferentes termos são usados na literatura específica para se referir à pesquisa feita por educadores a partir de sua própria prática na escola e/ou em sala de aula. Os mais comuns são: pesquisa-ação, investigação na ação, pesquisa colaborativa e pesquisa emancipatória”.

Os autores acima citados indicam ainda que, cada um destes termos, cunhados por autores como Lewin, Carr e Kemmis, dentre outros, traz consigo uma definição do termo pesquisa (DINIZ-PEREIRA; ZEICHNER, 2011).

No entanto, foram Cochran-Smith e Lytle (2002) que "tentaram sistematizar e descrever o que poderia ser uma tipologia de trabalho de investigação destes profissionais" (FIORENTINI; LORENZATO, 2006, p. 73). Para elas, a pesquisa dos professores pode ser definida como:

Um estudo sistemático e intencionado dos professores sobre seu próprio trabalho na sala de aula e na escola. [...] Com sistemático nos referimos fundamentalmente formas ordenadas de reunir e registrar informações, documentar as experiências que acontecem dentro ou fora da escola e criar uma espécie de registro escrito. [...] Com intencionado indicamos que a investigação dos professores é uma atividade planejada, isto é, não espontânea.

As mesmas autoras, afirmam ainda que, embora haja semelhanças entre as pesquisas feitas na universidade e as pesquisas dos professores, faz-se necessário considerar as principais diferenças entre elas. Uma delas é o rigor metodológico, o qual é composto pelos seguintes critérios: (1) as perguntas que as conduzem; (2) a generalização; (3) os fundamentos teóricos, e (4) a documentação utilizada e a análise.

Apresentaremos, logo abaixo, as ideias centrais destes critérios, uma vez que estão presentes nas dissertações de mestrado dos professores que ensinam matemática. As dissertações representam parte das sistematizações feitas por eles durante o desenvolvimento de atividades de pesquisa. Ao mesmo tempo, os critérios se configuraram enquanto categorias analítico-descritivas enquanto procurávamos responder a seguinte questão: afinal, quais são os conhecimentos produzidos por professores que ensinam matemática ao realizarem atividades de pesquisa, em um contexto específico, como o OBEDUC/Capes?

Nesse sentido, há de se considerar os estudos de Cochran-Smith e Lytle (2002) quando se referem ao primeiro critério indicado acima: as perguntas que conduzem as pesquisas dos professores. Segundo as autoras, as perguntas de pesquisa feitas pelos professores, ao contrário 
do que ocorre na universidade, "partem da experiência cotidiana deles e isto não é um assunto trivial". Podem "emergir das discrepâncias entre as intenções e os fatos [...]. Este processo de interrogação sobre a própria prática é muito reflexivo, imediato e altamente referenciado em contextos particulares tanto de aula, quanto dos alunos" (COCHRAN-SMITH; LYTLE, 2002, p. 35).

No que diz respeito ao critério generalização, as autoras são enfáticas ao afirmarem que tal critério "tem sido utilizado muitas vezes contra as investigações individuais dos professores em suas aulas, para reduzir o valor destas” (COCHRAN-SMITH; LYTLE, 2002, p. 41). Assim, "mais do que leis sobre a generalização na aula, o que necessitamos são indicadores concretos de como e porque algumas práticas são mais relevantes que outras nos contextos particulares de cada aula" (COCHRAN-SMITH; LYTLE, 2002, p. 41). Essa forma de pensar é compartilhada pelos "investigadores interpretativos quando demonstram que a compreensão de uma classe ajuda a entender melhor as outras" (COCHRAN-SMITH; LYTLE, 2002, p. 41).

Em relação aos fundamentos teóricos, as autoras afirmam que "não só há discussão sobre o estatuto científico das questões levantadas pelos professores" (COCHRAN-SMITH; LYTLE, 2002, p. 42), como também se observam:

Os desacordos sobre as formas com que a investigação dos professores se fundamenta teoricamente. [...] Podemos afirmar então que a noção de teoria como combinação de perspectivas pode ser perfeitamente compatível e também muito produtiva para compreender os processos de investigação dos professores. [...] A investigação dos professores por si mesma traz evidências dos esquemas teóricos subjacentes nas decisões e nas perguntas que os professores se fazem em suas aulas. (COCHRAN-SMITH; LYTLE, 2002, p. 44)

Quando o critério está relacionado à documentação e à análise, afirmam que: "as formas de documentação utilizadas na investigação dos professores se assemelham muito àquelas que tipicamente" (COCHRAN-SMITH; LYTLE, 2002, p. 44) são utilizadas pelos pesquisadores acadêmicos, "sobretudo quando nos referimos aos processos interpretativos da investigação" (COCHRAN-SMITH; LYTLE, 2002, p. 44). Os professores utilizam notas de campo, entrevistas, documentos de aula, documentos de avaliação, bem como gravadores, filmagens etc. Realizam investigações qualitativas, assim como os professores universitários. Quando estes professores da escola

[...] enfrentam a tarefa de analisar os fenômenos que observaram e sua dinâmica, utilizam esquemas práticos de interpretação do que ocorre, construindo uma perspectiva muito distinta da que construiria um observador externo, ainda que este último tivesse um acesso ao campo de forma continuada ou bem realizasse uma etnografia profunda em alguma aula. (COCHRAN-SMITH; LYTLE, 2002, p. 45)

Assim, para que se possam compreender os conhecimentos produzidos pelos professores que ensinam matemática, a partir dos critérios estabelecidos pelas autoras, apresentaremos o 
contexto que possibilitou que os professores estivessem em atividades de pesquisa e pudessem sistematizá-las, a partir de dissertações de mestrado.

\section{Contextualizando as atividades de pesquisa desenvolvidas pelos professores da Educação Básica no âmbito do OBEDUC-UFSCar}

Durante o período de janeiro de 2009 a dezembro de 2012, no âmbito do Programa OBEDUC, da Universidade Federal de São Carlos (UFSCar), quarenta pessoas - dentre elas, licenciandos, professores da Educação Básica que ensinam matemática e/ou física e pesquisadores das áreas de ensino de física e da educação matemática - estiveram envolvidas em atividades de pesquisa. Isso significou, em outras palavras, que licenciandos e professores da Educação Básica receberam bolsas para participar do projeto "Produtos educacionais no Mestrado Profissional em Ensino de Física e Matemática: itinerários de desenvolvimento, implementação e avaliação, a partir da rede de pesquisa participante Escola-Universidade"; e tinham financiamento para desenvolver suas pesquisas, bem como, organizar e participar de eventos acadêmicos. Há de se ressaltar, ainda, que a equipe participava de grupos de estudo e de pesquisa; organizava e planejava, coletivamente, atividades e projetos de ensino. E, especialmente, os professores da Educação Básica estavam vinculados a programas de pós-graduação (Acadêmico ou Profissional).

Assim, os integrantes do OBEDUC da UFSCar sintetizaram suas aprendizagens e seus conhecimentos por meio de diferentes gêneros textuais, tais como: artigos, relatos de pesquisa, crônicas, iniciações científicas e dissertações de mestrado. As ações de todos os integrantes foram feitas de forma compartilhada e promoveram a construção de redes de convivência (BOHM, 2005) constituídas por grupos de profissionais, com perfis acadêmicos distintos, que atuam nas licenciaturas e nas escolas públicas, promovendo o diálogo (BOHM, 2005) e a reflexão sobre o atual ensino de física e de matemática. As redes possuíam singularidades e particularidades, e procuraram desenvolver um trabalho integrado e compartilhado.

Vale a pena ressaltar que as redes de convivência representaram espaços institucionalizados, na universidade, que incentivaram, conforme apontam Rêgo e Rêgo (2006, p. 41), a "melhoria da formação inicial e continuada" de professores, as quais promoveram a "integração das ações de ensino, pesquisa e extensão". Possibilitaram: (1) o estreitamento das relações entre escola e universidade, de forma que as duas instituições pudessem atuar em parceira na solução de alguns problemas educacionais relacionados ao ensino de Matemática, apontados pelos professores. Nesse sentido, tanto os licenciandos e pesquisadores, quanto os professores das escolas buscaram a melhoria do ensino e constituíram um espaço de divulgação e de implantação de uma cultura de base científica; (2) o estímulo à "prática da pesquisa em sala de aula" baseada em uma sólida formação teórica e prática, e (3) o desenvolvimento de "projetos de parceria com os sistemas locais de ensino [...]” (RÊGO; RÊGO, 2006, p. 41).

Ressalta-se ainda que, neste contexto, as redes de convivência tiveram o intuito de proporcionar, aos professores que ensinam física e/ou matemática, a oportunidade de se desenvolverem profissionalmente, teorizando sobre a prática e praticando a teoria que estudavam, compartilhando seus conhecimentos por meio de vivências de atividades de pesquisa científica. 
Nesse sentido, licenciandos, professores da Educação Básica e pesquisadores dialogaram, conforme defende Bohm (2005), sobre o que se almeja e o que realmente se pratica no ensino de física e na educação matemática. Tal diálogo continha culturas escolares e acadêmicas distintas que fundamentaram as ações de todos os integrantes.

Os pressupostos teóricos que conduziram as ideias centrais das investigações foram: (1) o professor deve ser considerado como profissional crítico-reflexivo que toma decisões sobre o currículo; (2) o trabalho em equipe na escola deve ser considerado para que possa haver a consolidação do trabalho e da inovação pedagógicos; (3) a formação de redes de investigação participantes é necessária, para que se possa almejar a melhoria do ensino, a partir do desenvolvimento de pesquisas com os professores sobre e na escola.

As atividades de pesquisa consideraram, pelo menos, dois aspectos que se fundamentam na pesquisa participante: negociação e diálogo, os quais permitiram que a equipe, a cada encontro, reafirmasse o compromisso com a profissionalização do professor e com a produção de conhecimentos pedagógicos que dialogavam com as problemáticas presentes nas práticas educativas, tanto dos licenciandos quanto dos professores das escolas e da universidade que estavam atuando nas salas de aula. Tais problemáticas, bem como os estudos que ocorreram sistematicamente nos grupos de estudos e de pesquisa, acolheram "diferentes vozes" e procuraram considerar "o diálogo com saberes advindos da experiência de viver [...]" (SCHMIDT, 2006, p. 28) de cada um dos integrantes.

Pode-se afirmar que um dos aspectos importantes da pesquisa participante e, consequentemente, das redes de convivência, o diálogo, foi estabelecido entre pessoas com culturas escolares e acadêmicas diferenciadas, as quais procuraram colaborar, sistematicamente, a partir de reflexões que envolveram o ensino de física e/ou de matemática. Dessa forma, as redes se constituíram em "uma espécie de microcosmo da cultura global. Então a questão cultural - o significado coletivamente compartilhado - está começando a aparecer” (BOHM, 2005, p. 45) nos trabalhos produzidos. Claro que as diferentes culturas escolares e acadêmicas fazem parte da cultura global sobre o pensar e o fazer o ensino de física e/ou matemática. Logo, não contêm um pensamento único. Contêm dúvidas, discordâncias e dificuldades. É por este motivo que concordamos com Bohm (2005) quando afirma que:

[...] o objetivo do diálogo não é analisar as coisas, ganhar discussões ou trocar opiniões. Seu propósito é suspender as opiniões e observá-las ouvir os pontos de vista de todos, suspendê-los e a seguir perceber o que tudo isso significa. Se pudermos perceber o que significam todas as nossas opiniões compartilharemos um conteúdo comum, mesmo se não concordarmos completamente. (BOHM, 2005, p. 65, grifo do autor)

Um dos conteúdos comuns compartilhados pela equipe foi a reflexão sobre as pesquisas de licenciandos e de professores que foram elaboradas pelas duas áreas. Houve, aqui, a intenção de se estabelecer uma "consciência participativa" entre os professores da Educação Básica, os licenciandos e os pesquisadores, no sentido de se analisar "algum modo de sairmos de nossas dificuldades" (BOHM, 2005, p. 79) relacionadas ao ensino. Estas dificuldades diziam respeito a se pensar e a fazer o ensino de física e o ensino de educação matemática na Educação Básica. 
A partir do estabelecimento do diálogo e das negociações que foram feitas constantemente, o poder dos professores e dos licenciandos parecia estar crescendo "mais rapidamente do que o número de pessoas que o integravam" (BOHM, 2005, p. 45), rompendo com o ciclo vicioso que fomenta a formação continuada de professores, uma vez que, apesar de investimentos governamentais neste tipo de formação, os dados estatísticos, disponibilizados pelo Instituto Nacional de Estudos e Pesquisas Educacionais Anísio Teixeira (2003) e pelo Sistema de Avaliação de Rendimento Escolar do Estado de São Paulo - Saresp (SÃO PAULO, 2007), mostram que o diálogo que estamos propondo, infelizmente, não ocorre continuamente entre licenciandos e professores da Educação Básica.

Outro aspecto da pesquisa participante que se apresentou durante o desenvolvimento das atividades de pesquisa está relacionado às “diferentes formas de divulgação dos trabalhos", os quais "apontam, também, na direção de uma democratização do conhecimento, abrindo a possibilidade de colaborações diferenciadas na produção de textos com diferentes linguagens e destinatários ou de outros objetos culturais [...]" (SCHMIDT, 2006, p. 29).

Não podemos nos esquecer de mencionar, ainda, que o compartilhamento de conhecimentos - dentre eles, o conhecimento sobre o ensino de matemática - entre os professores, ficou muito difícil, quando constatamos que a jornada de trabalho deles, sobretudo daqueles que lecionam nas séries finais do Ensino Fundamental e Ensino Médio, ultrapassava trinta horas semanais, comprometendo a qualidade do trabalho docente. Este fato acabou refletindo-se no baixo índice de aproveitamento dos estudantes, conforme apontam os dados do Instituto Nacional de Estudos e Pesquisas Educacionais Anísio Teixeira (2003).

\section{Analisando as pesquisas de professores que ensinam matemática}

O Quadro 1 indica as dissertações de mestrado elaboradas, no âmbito do OBEDUC -UFSCar, pelos professores que ensinam matemática.

Ao lermos a dissertação de Mendes (2012), por exemplo, chama-nos a atenção quando o professor se refere às dificuldades que teve ao desenvolver sua pesquisa, enquanto lecionava, por mais de trinta horas semanais. Ao mesmo tempo em que o conhecimento sobre suas dificuldades tornou-se público, o professor explicitou uma proposta direcionada aos políticos e aos administradores da Educação, corroborando com os estudos de Cochran-Smith e Lytle (2002), quando indicam que as pesquisas dos professores contêm conhecimentos locais e conhecimentos públicos:

Não posso deixar de mencionar sobre a dificuldade que tive em pensar, elaborar e desenvolver atividades orientadoras de ensino e cursar as disciplinas do mestrado e paralelamente a isso, ministrando 33 aulas semanais na rede Estadual de Ensino. Para amenizar esta dificuldade, uma proposta de solução seria oferecer bolsas de estudos para professores em exercício nas escolas públicas ou privadas, durante o tempo que estão cursando o mestrado. Com isso, diminuiriam sua quantidade de aula e, consequentemente, a qualidade de seu aprendizado aumentaria. (MENDES, 2012, p. 145) 
Quadro 1. Pesquisas desenvolvidas no âmbito do OBEDUC-UFSCar

\begin{tabular}{|c|c|c|c|c|}
\hline \multicolumn{5}{|c|}{ Área: Educação Matemática } \\
\hline $\begin{array}{c}\text { Autores } \\
\text { (Ano) }\end{array}$ & Título da dissertação & $\begin{array}{l}\text { Produtos } \\
\text { educacionais } \\
\text { elaborados }\end{array}$ & Conteúdos & $\begin{array}{l}\text { Perspectivas } \\
\text { teóricas }\end{array}$ \\
\hline $\begin{array}{c}\text { Borges } \\
(2011)\end{array}$ & $\begin{array}{l}\text { Ideias algébricas explicitadas por } \\
\text { estudantes da EJA em espaços } \\
\text { não formais: o caso do cursinho de } \\
\text { Ribeirão Preto }\end{array}$ & $\begin{array}{l}\text { Folhas de } \\
\text { atividades }\end{array}$ & Função & $\begin{array}{l}\text { AOE (MOURA) } \\
\text { - Situações } \\
\text { emergentes do } \\
\text { cotidiano) }\end{array}$ \\
\hline $\begin{array}{c}\text { Gomes } \\
(2010)\end{array}$ & $\begin{array}{l}\text { Uma proposta de ensino } \\
\text { envolvendo geometria fractal para } \\
\text { o estudo de semelhança de figuras } \\
\text { planas }\end{array}$ & $\begin{array}{l}\text { Folhas de } \\
\text { atividades }\end{array}$ & $\begin{array}{l}\text { - Geometria fractal } \\
\text { - Semelhanças de } \\
\text { figuras planas }\end{array}$ & $\begin{array}{l}\text { Aulas } \\
\text { investigativas } \\
\text { (PONTE) } \\
\text { - Sequências } \\
\text { didáticas }\end{array}$ \\
\hline $\begin{array}{l}\text { Mendes } \\
(2012)\end{array}$ & $\begin{array}{l}\text { Da resolução de quebra-cabeças } \\
\text { em sala de aula à aplicabilidade } \\
\text { no cotidiano de uma marmoraria: } \\
\text { o que os estudantes do } 9^{\circ} \text {. ano } \\
\text { do Ensino Fundamental falam e } \\
\text { escrevem sobre o conceito de área }\end{array}$ & $\begin{array}{l}\text { Folhas de } \\
\text { atividades e } \\
\text { quebra-cabeças }\end{array}$ & $\begin{array}{l}\text { Área de figuras } \\
\text { planas }\end{array}$ & $\begin{array}{l}\text { AOE (MOURA) } \\
\text { - Jogos } \\
\text { - Situações } \\
\text { emergentes do } \\
\text { cotidiano } \\
\text { Histórico-cultural }\end{array}$ \\
\hline $\begin{array}{c}\text { Paez } \\
(2012)\end{array}$ & $\begin{array}{l}\text { Formação de sentidos e } \\
\text { significados matemáticos por meio } \\
\text { da leitura da obra: O homem que } \\
\text { calculava }\end{array}$ & Fichas avaliativas & $\begin{array}{l}\text { - Proporção; } \\
\text { - Área e volumes } \\
\text { de figuras } \\
\text { geométricas; } \\
\text { - Potenciação; } \\
\text { - Teorema de } \\
\text { Pitágoras; } \\
\text { - Valor posicional; } \\
\text { - Base de } \\
\text { numeração; } \\
\text { - Composição e } \\
\text { decomposição } \\
\text { numérica e } \\
\text { geométrica; } \\
\text { - Senso numérico }\end{array}$ & $\begin{array}{l}\text { (VYGOTSKY) } \\
\text { - Livro } \\
\text { paradidático: } \\
\text { O homem que } \\
\text { calculava (Malba } \\
\text { Tahan) }\end{array}$ \\
\hline $\begin{array}{l}\text { Silva } \\
(2012)\end{array}$ & $\begin{array}{l}\text { Elaborações de estudantes do } 7^{\circ} \\
\text { ano do Ensino Fundamental sobre } \\
\text { números inteiros e suas operações }\end{array}$ & Jogo & Números inteiros & $\begin{array}{l}\text { AOE (MOURA) } \\
\text { - Jogos } \\
\text { - Laboratório de } \\
\text { manipulação } \\
\text { virtual } \\
\text { - Brincadeiras }\end{array}$ \\
\hline $\begin{array}{c}\text { Vazquez } \\
(2011)\end{array}$ & $\begin{array}{l}\text { O ensino de análise combinatória } \\
\text { no Ensino Médio por meio de } \\
\text { atividades orientadoras em uma } \\
\text { escola estadual do interior paulista }\end{array}$ & $\begin{array}{l}\text { Folhas de } \\
\text { atividades }\end{array}$ & $\begin{array}{l}\text { Análise } \\
\text { combinatória }\end{array}$ & $\begin{array}{l}\text { AOE (MOURA) } \\
\text { - Situações } \\
\text { emergentes do } \\
\text { cotidiano }\end{array}$ \\
\hline
\end{tabular}

Fonte: Elaborado pela autora.

Ao falarem sobre as preocupações que têm e sobre o porquê elas se tornaram problemáticas de suas pesquisas, os professores indicam-nos que estão relacionadas ao conhecimento que 
possuem tanto sobre as dificuldades dos estudantes quanto sobre as relações que podem fazer entre os conteúdos que ministram e as metodologias de ensino que utilizam em suas práticas. Indicam-nos, ainda, que pretendem desenvolver os conteúdos matemáticos, de forma que os estudantes possam fazer investigações e ficarem curiosos com a matemática.

O interesse em trabalhar com Geometria fractal vem do seu aspecto atraente que pode trazer muitas questões para investigação, além da mobilidade de se trabalhar com uma variedade de conteúdos matemáticos. (GOMES, 2010, p. 17)

Já no início do mestrado, a oportunidade do ingresso no Projeto Observatório da Educação [...] e a participação no GEM [...], motivaram-nos ainda mais a entender as diversas formas que os estudantes do cursinho usavam para resolver situações-problema que necessitavam de recursos algébricos oferecidos pela grade curricular da escola formal. (BORGES, 2011, p. 14)

O início do trabalho com a combinatória mostra-se particularmente problemático para muitos alunos, que mecanicamente tentam descobrir a que tipo de agrupamento - arranjo, permutação ou combinação - o problema pertence, para depois resolvê-lo utilizando a fórmula adequada. Diante disso, surgiu o interesse em desenvolver e em aplicar atividades diferenciadas buscando despertar a curiosidade e a investigação matemática numa área que usualmente é pouco explorada, a Análise Combinatória. (VAZQUEZ, 2011, p. 9)

A ideia dessa investigação nasceu a partir de dificuldades enfrentadas por nós, ao ministrarmos aulas, sobre os números inteiros no ensino fundamental. Percebemos que os alunos do $7^{\circ}$ ano não entendiam o conteúdo programado para o primeiro bimestre do ano letivo. (SILVA, 2012, p. 11)

As dificuldades na compreensão e na realização de um trabalho com leitura nas aulas de Matemática levaram ao estudo e execução desta pesquisa [...]. Parecia-nos que o desenvolvimento de atividades deste tipo poderia ajudar os estudantes em sua leitura de mundo e na produção de sentidos e significação dos conteúdos matemáticos. (PAEZ, 2012, p. 12)

A minha experiência em sala de aula mostra que o conteúdo de áreas de polígonos, tema deste estudo, de acordo com a Proposta Curricular do Estado de São Paulo (SEE/SP, 2008), faz parte do currículo do $4^{\circ}$ bimestre do $8^{\circ}$ ano, mas os estudantes do último ano do Ensino Fundamental das salas onde leciono não estudaram esse conteúdo. [...] estes fatos que presenciei e, infelizmente, ainda presencio, me influenciaram na 
escolha do tema Áreas de Figuras Planas para desenvolver a dissertação de mestrado. (MENDES, 2012, p. 23; 26)

Concordamos com Cochran-Smith e Lytle (2002) que as problemáticas levam às perguntas interessantes que passam a conduzir as pesquisas dos professores. Por este motivo, as questões não são triviais e estão relacionadas às suas experiências cotidianas, conforme segue abaixo. As perguntas que Gomes (2010), Borges (2011), Silva (2012), Paez (2012) e Mendes (2012) explicitaram em suas dissertações são:

Como se dá o processo de elaboração, aplicação, análise e recepção pelos estudantes de um material didático envolvendo Geometria fractal para o aprendizado do conceito de semelhança de figuras na $8^{\mathrm{a}}$ série do Ensino Fundamental? (GOMES, 2010, p. 17)

Quais são as ideias algébricas explicitadas por estudantes de EJA quando vivenciam, em um espaço não formal, situações-problema? (BORGES, 2011, p. 6)

Quais elaborações os estudantes manifestam e/ou explicitam enquanto vivenciam as atividades orientadoras de ensino com números inteiros? (SILVA, 2012, p. 6)

Quais são os sentidos e significados matemáticos que podem ser produzidos por estudantes do $8^{\circ}$ e $9^{\circ}$ anos do Ensino Fundamental, de uma escola pública estadual da cidade de [Nome do Município], interior do Estado de São Paulo, a partir da leitura das estórias do livro "O Homem que Calculava”? (PAEZ, 2012, p. 7)

O que estudantes do $9^{\circ}$ ano do Ensino Fundamental falam e escrevem sobre o conceito de área enquanto vivenciam atividades orientadoras de ensino, tanto na sala de aula, quanto no contexto de uma marmoraria? (MENDES, 2012, p. 10)

No que diz respeito àqueles que defendem que as pesquisas dos professores, para serem validadas enquanto conhecimento científico, precisam ter respostas generalizáveis, vale a pena prestar atenção no que dizem os professores Mendes (2012) e Silva (2012) sobre as singularidades e as particularidades presentes em suas turmas quando analisam os dados que construíram:

A análise dos dados, que não são generalizáveis, revelou que: a grande maioria dos estudantes generalizam verbalmente as fórmulas para calcular as áreas propostas, mas não conseguem formalizar essa fala matematicamente, fazendo uso da álgebra, da representação algébrica. A maioria dos estudantes, nesta faixa etária, prestes a concluir o ensino fundamental, ainda não consegue generalizar fórmulas, ainda que se faça 
uso de materiais didáticos elaborados por eles mesmos, ou seja, durante o desenvolvimento das atividades, apenas dois dos trinta estudantes conseguiram fazer a generalização solicitada. (MENDES, 2012, p. 139-140)

A aula deve ser preparada e adaptada levando em conta as particularidades da turma. Em um estado tão grande como o nosso, cada região tem suas necessidades e se tratando de escolas e salas de aulas essas particularidades se restringem ainda mais. $\mathrm{O}$ universo de sala de aula é único, pois cada indivíduo é único então é um erro generalizar a metodologia da aula como se fosse uma produção em série. Pois, a escola não é uma fábrica, ela não produz robôs, ela deve formar pensamentos e atitudes e isso não se faz com modelos únicos. Mesmo em uma escola com três salas da mesma faixa etária vamos encontrar enormes diferenças. [...] na nossa escola, com o mesmo professor, as atividades transcorreram de modo diferente, pois cada aluno, cada turma, leva em conta vivências para fazerem suas elaborações. Sendo assim isso não ocorrerá de maneira uniforme. Com esse trabalho não temos a pretensão de generalizar nenhuma conclusão, pois já mencionamos a individualidade de cada turma. (SILVA, 2012, p. 104-106)

Entendemos que, na medida em que compreendermos melhor os resultados das pesquisas individuais dos professores que ensinam matemática, a partir das perguntas não triviais que fazem, poderemos compreender por que as práticas que desenvolvem no interior das salas de aula podem ser consideradas relevantes. Ao mesmo tempo, podemos constatar que os conhecimentos que produzem sobre o ensino de matemática não estão dissociados dos conhecimentos relacionados às dificuldades que enfrentam diariamente.

Quando analisamos os conhecimentos relacionados aos fundamentos teóricos e metodológicos que têm conduzido as ações e as análises que os professores têm feito sobre os processos de ensino e de aprendizagem de seus estudantes constatamos que, das seis pesquisas desenvolvidas até aqui, pelos professores, quatro delas se fundamentam nos pressupostos da Atividade Orientadora de Ensino (AOE), propostos por Moura (2010), os quais buscam sustentação na Teoria da Atividade, preconizada por Leontiev (1983).

A AOE promove a mobilização daqueles que ensinam e daqueles que aprendem os conteúdos de matemática, a partir de "situações desencadeadoras de aprendizagem" que podem ser "materializadas por meio de diferentes recursos metodológicos", dentre eles, "o jogo, as situações emergentes do cotidiano e história virtual do conceito” (MOURA, 2010, p. 100). Tais pressupostos foram eleitos pelos professores enquanto estudavam os teóricos que os auxiliariam a fundamentar as pesquisas e a elaborar os produtos educacionais, representados na forma de folhas de atividades, jogos etc, que contribuiriam com a organização do ensino e da aprendizagem nas salas de aula. Para Silva (2012) e Vazquez (2012):

A introdução dos jogos nas atividades teve por objetivo proporcionar aulas mais descontraídas e prazerosas para todos os envolvidos no processo, conforme aponta-nos os estudos de Moura quando afirma que 
as Atividades Orientadoras de Ensino podem ser configuradas, através de jogos. (SILVA, 2012, p. 56)

As atividades foram elaboradas de forma que o conteúdo de Análise Combinatória fosse trabalhado de uma maneira diferenciada do tradicional, buscando despertar o interesse e a curiosidade dos alunos. Consideramos tais atividades como sendo atividades orientadoras de ensino [...]. As atividades de Análise Combinatória tinham por intenção abordar o assunto sem o abusivo uso de fórmulas como tradicionalmente acontece, para que o conteúdo passasse a ser assumido como algo dinâmico que pudesse ser construído, transformado para atender os objetivos, as concepções. Buscou-se, através dessas atividades, uma prática educativa na qual o professor tem um papel mediador entre o objeto de conhecimento e os sujeitos da aprendizagem, não mais como um simples expositor e os alunos como meros receptores. (VAZQUEZ, 2012, p. 48-49)

Quando tratam dos conhecimentos sobre os conteúdos abordados e sua relação com as atividades propostas em sala de aula, os professores afirmam que:

A Geometria Fractal, mesmo sendo considerada um ramo recente da Matemática e alvo de discussões, além do estudo ainda incipiente sob alguns aspectos, pode ser amplamente utilizada em salas de aula da Educação Básica. Ela pode se manifestar na forma de muitas atividades a serem desenvolvidas pelos estudantes, além de despertar o interesse destes pelo assunto. (GOMES, 2010, p. 132)

As quatro situações-problema construídas por nós, durante o desenvolvimento das aulas, mostraram-nos que é possível ensinar conteúdos presentes na grade curricular "oficial", de acordo com os Parâmetros Curriculares Nacionais, porém de maneira dialógica, permitindo que o estudante consiga, com a ajuda do grupo, construir determinados conceitos, o que, por algum motivo, não fora feito na escola básica, ou ainda, refletir com os estudantes sobre algumas concepções consideradas equivocadas, as quais foram de certa forma, aprendidas durante sua vida estudantil. (BORGES, 2011, p. 81)

Pôde-se constatar que as atividades orientadoras foram essenciais para um melhor desempenho dos estudantes que se sentiram mais seguros e confiantes para a realização de novas atividades. (VAZQUEZ, 2011, p. 7)

Vale ressaltar a relevância das rodas de discussões que aconteciam a cada etapa do trabalho. Esse era um momento de extrema importância para nós. Nesse instante o diálogo era uma porta aberta para o pensamento dos alunos. As elaborações são formuladas no pensamento e o diálogo é 
o único caminho. O professor deve estar atento, pois essas elaborações são explicitadas tanto no diálogo com ele, quanto nas conversas entre os alunos, como exemplificamos nesse texto. (SILVA, 2012, p. 105)

As atividades que conciliam dobradura, recorte, pintura e quebra-cabeça, além de facilitar a aprendizagem de conceitos geométricos como ponto médio de um segmento, altura de um triângulo, base de um triângulo, favorecem também a aprendizagem do cálculo de áreas de polígonos e a dedução de fórmulas para calcular a área dos mesmos. (MENDES, 2012, p. 140)

Para os estudantes da Educação Básica podemos considerar que o uso de textos literários na produção de sentido e significados a conceitos matemáticos implica no estímulo a criatividade e liberdade de pensamento para o levantamento de hipóteses, argumentação em defesa de suas ideias, revisão de conceitos constituídos de forma formal - pela educação escolar - ou informal - estabelecida pelas relações com o meio, reflexão sobre o uso da linguagem matemática oral e escrita com representação própria distinta da utilizada na comunicação cotidiana, além de perceber a Matemática como Ciência, como meio para interpretar fenômenos naturais e sociais. (PAEZ, 2012, p. 115)

A partir dos conhecimentos apontados acima, os produtos educacionais produzidos e organizados, coletivamente, pelos professores podem ser definidos como "unidades entre ensino e aprendizagem” (MOURA, 2010, p. 94), pois consideram as necessidades, os motivos, as ações e as operações presentes no cotidiano de todos os envolvidos no processo ensino-aprendizagem. Logo, tais produtos, elaborados e organizados para auxiliar a responder às perguntas de pesquisa, podem revelar o conhecimento que professores têm sobre o ensino de matemática e das salas de aula que conduzem.

Aqui, o professor concretiza os "objetivos sociais objetivados no currículo escolar, organiza o ensino: define ações, elege instrumentos e avalia o processo de ensino e aprendizagem” (MOURA, 2010, p. 94), uma vez que:

Os elementos característicos da AOE (necessidades, motivos, ações, operações) permitem que ela seja elemento de mediação entre a atividade de ensino e a atividade de aprendizagem. Logo, a atividade de ensino e a atividade de aprendizagem só podem ser separadas para fins de explicação didática; entretanto, o motivo de ambas deve coincidir para que sejam concretizadas. Tal motivo é a apropriação pelos estudantes, da experiência histórica acumulada, pela via do pensamento teórico e dos conceitos científicos, visando ao desenvolvimento do psiquismo, das funções psíquicas superiores. Não há sentido na atividade de ensino se ela não se concretiza na atividade de aprendizagem; por sua vez, não existe a atividade de aprendizagem intencional se ela não se dá de forma consciente e organizada por meio da atividade de ensino. (MOURA, 2010, p. 100) 
Logo, os produtos educacionais elaborados pelos professores desencadeiam situações de aprendizagem. Conectam a atividade de ensino com a atividade de aprendizagem, por meio de situações de aprendizagem que são organizadas e elaboradas pelos professores e vivenciadas pelos estudantes que frequentam as aulas destes profissionais. Nesse contexto, os professores são convidados a serem autores e coautores dos produtos que utilizam em suas salas de aula ao desenvolverem as pesquisas, ficando muito à vontade para compartilhar suas experiências, e se mostram disponíveis para aprender continuamente. As falas de Borges (2011) e Mendes (2012) são representativas deste fato:

Com a ida a Encontros e Congressos pudemos ver de perto o trabalho de outros pesquisadores e também mostrar o nosso, recebendo críticas construtivas que ajudaram em sua formatação final. [...] as situações-problema surgiram das nossas reflexões e diálogos. (BORGES, 2011, p. 16)

É importante ressaltar que, antes do desenvolvimento das atividades em sala de aula, refletimos sobre elas durante o Mini Curso intitulado: Da resolução de quebra-cabeças à constituição das fórmulas para calcular áreas de polígonos, apresentado no X-ENEM, Encontro Nacional de Educação Matemática, ocorrido em julho de 2010, em Salvador-BA, fato que trouxe muitas contribuições dos participantes, todos os professores e estudantes de matemática. (MENDES, 2012, p. 62)

Podemos perceber, até aqui, que as pesquisas dos professores e os produtos educacionais que são parte integrante delas são considerados resultado de um processo reflexivo e contextualizado, que contém conhecimentos experienciais e teóricos. Tais pesquisas contêm fluência, movimento porque representam a dinâmica das aulas. Mostram as situações de aprendizagem, as quais definem os modos ou procedimentos que colocarão os conteúdos em jogo na sala de aula. Indicam como os professores elegem os recursos metodológicos adequados aos objetivos e ações elencados por eles, e, por último, indicam os processos de análises e sínteses feitas pelos professores. Nesta perspectiva, tal qual a AOE, as pesquisas dos professores representam a unidade entre ensino e aprendizagem. São conhecimentos produzidos sobre o ensino de matemática.

Quando analisamos a documentação utilizada como instrumento de construção dos dados pelos professores, enquanto desenvolvem suas pesquisas, concordamos com Cochran -Smith e Lytle (2002) que, os documentos são muito parecidos com aqueles que também são utilizados pelos professores da universidade, uma vez que fizeram uso de:

- Diários de bordo e questionários (GOMES, 2010, p. 25);

- Documentos oficiais: Parâmetros Curriculares Nacionais (PCN) e Proposta Curricular para o ensino de Matemática, elaborada pela Secretaria da Educação do Estado de São Paulo em 2008 (GOMES, 2010, p. 29; MENDES, 2012, p. 17; SILVA, 2012, p. 55; VAZQUEZ, 2011, p. 75);

- Relatos de aula (BORGES, 2011, p. 42);

- Livro Experiências Matemáticas da $\sigma^{\mathrm{a}}$ série, publicado pela Secretaria de Educação do Estado de São Paulo, autoavaliação dos estudantes (SILVA, 2012, p. 55-56); 
- Livro paradidático (PAEZ, 2012, p. 27); “[...] considerei, durante a elaboração das atividades, a síntese histórica do conceito de área que envolve a composição e decomposição de figuras geométricas presentes nos estudos de Boyer (1974)" (MENDES, 2012, p. 30).

As análises feitas pelos professores, explicitadas e sintetizadas em suas pesquisas sobre o conhecimento que têm em relação ao ensino de matemática que ministram podem nos indicar caminhos para repensarmos os processos de ensino e de aprendizagem de matemática, de forma que todos os envolvidos - estudantes, professores e gestores - possam estar em atividade, compreendendo tanto a sala de aula quanto as facilidades e dificuldades de todos nós em relação a aprender e a ensinar e, consequentemente, traçar outros caminhos para que a Educação Básica brasileira consiga dar um salto qualitativo. Dessa forma, afirmam que quando:

O estudante diz que as aulas em que ele aprendeu, ele gostou; por outro lado, na que ele não aprendeu nada, a aula ficou chata. Isto nos leva a crer que a disposição do estudante em falar bem da aula, gostar ou manifestar mais interesse tem a ver com o aprendizado que ele sentiu com a referida aula. (GOMES, 2010, p. 93)

As dificuldades que os estudantes da escola tradicional apresentam como a dificuldade em acreditar que uma fórmula pode ser aplicada (ou generalizada) em diversos contextos, não ocorre por acaso. Não se trata apenas de lacunas no cumprimento do currículo, ou de defasagens no conteúdo. As dificuldades apresentadas por eles surgem a partir do momento em que o contexto social, sua história de vida, suas perspectivas, valores e objetivos são ignorados ou neutralizados por uma cultura escolar que prioriza o conteúdo, que entende que a qualidade do Ensino é proporcional ao volume de conteúdo oferecido aos estudantes. (BORGES, 2011, p. 87)

O entendimento efetivo da maioria dos alunos se deu no momento em que puderam manipular quantidades negativas. Mesmo que a representação em certos momentos não era matematicamente a mais adequada, pois quando tiravam tampinhas vermelhas estavam multiplicando negativos. No entanto, esse processo contribuiu para o entendimento e a apropriação da propriedade e puderam assim fazer a transferência do conhecimento e fazer inferências. (SILVA, 2012, p. 106-107)

Quando os estudantes vivenciam a relação entre teoria e prática no contexto de uma marmoraria, compreendem como a teoria se aplica em contextos reais ou simulados. Com isso, o trabalho enquanto produção de bens e serviços revelou-se importante para conectar os conteúdos do currículo com a realidade. Nesse sentido, afirmo que, quando a aprendizagem ultrapassa os muros da escola e caminha para contextos reais ou simulados, ganha uma nova dimensão para os estudantes, onde podem propor soluções, se posicionar criticamente e podem mobilizar 
seus conhecimentos de vida e de Matemática para o entendimento da vida social, comercial e política. (MENDES, 2012, p. 141)

Mas, podemos perceber que os estudantes foram além dos conceitos matemáticos, eles também atribuíram significado às relações humanas apresentadas pelas personagens do livro como: ser justo ou ser aproveitador; ter distinção ou igualdade entre irmãos; a condição da mulher muçulmana e a mulher brasileira; as aulas orais proferidas pelo calculista à filha do xeique e as aulas recebidas pelos estudantes brasileiros; a religiosidade; o pagamento de dote; a relação entre trabalhador e empregador na agricultura, aqui no Brasil; a importância do salário e do consumo na sociedade capitalista, entre tantos outros aspectos que se encontram registrados nos vídeos e que não puderam ser apresentados nesta pesquisa por conta do tempo restrito (dois anos) dado a sua execução. (PAEZ, 2012, p. 115)

\section{À guisa de conclusão}

Quando os professores que ensinam matemática estão em atividade de pesquisa, indicam que investigar as situações reais das salas de aulas sobre o ensino de matemática permite com que explicitem conhecimentos relacionados à dinâmica das salas de aula, por meio das relações que fazem, na medida em que analisam os processos de ensino e de aprendizagem ou seja, praticam a teoria que estudam, uma vez que analisam, selecionam e criticam, de forma compartilhada, os textos, as atividades, os materiais didáticos que recebem, incluindo-se aí, as propostas curriculares. Podem transpor a prática para a teoria e vice-versa. Podem questionar a teoria e buscar aquela que melhor se adeque às suas salas de aula, considerando as particularidades e singularidades delas.

Dessa forma, as ações, sistematizadas nas dissertações articulam-se em torno do compromisso da formação continuada de professores, que prevê a intervenção na realidade educacional, mediante pesquisas que tratam da prática e da sistematização dos conhecimentos educacionais que estão postos. Ao mesmo tempo, mostram a necessidade de se investir em atividades de pesquisas que possam ser consideradas propostas de formação continuada de professores, a partir da incorporação dos estudos sobre a formação crítica e reflexiva e a ação investigativa dos professores; rompendo, assim, com um tipo de formação continuada fundamentada na racionalidade técnica, a qual prioriza apenas os conteúdos matemáticos, especialmente aqueles produzidos nas universidades.

Permitem-nos conhecer o que ocorre dentro e fora das salas de aula, conectam os conhecimentos locais e públicos dos professores, promovendo que conheçam melhor suas práticas, a partir do delineamento de algumas ações a serem desenvolvidas no âmbito da Educação Básica. Permitem-nos, ainda, que possamos perceber as fragilidades existentes no contexto educacional, bem como os caminhos que traçam, a fim de suprir as necessidades da sala de aula, se posicionando politicamente frente a sua realidade; bem como analisar, juntamente com os professores, as demandas da sala de aula, uma vez que podem variar muito. Mostram-nos que, nem sempre, 
as demandas e as dificuldades que os estudantes têm, em relação aos conhecimentos matemáticos, coincidem com aqueles que os pesquisadores indicam.

É por este motivo que, quando os professores estão em atividades de pesquisa, temos de considerar a escola tanto quanto a universidade como espaço de produção de conhecimentos que promovem a análise das práticas escolares.

Podemos inferir que os conhecimentos que os professores produzem sobre o ensino de matemática estão relacionados: aos conhecimentos das dificuldades deles e dos estudantes, quando a temática envolve os processos de ensino e de aprendizagem; à elaboração e organização de atividades que possam atender as expectativas dos estudantes; aos sentimentos dos estudantes em relação às aulas de matemática, e conhecimentos relacionados ao uso de sínteses históricas, documentos oficiais e materiais disponibilizados para o ensino.

\section{Referências}

BOHM, D. Diálogo: comunicação e redes de convivência. São Paulo: Palas Athena, 2005.

BORGES, A. A. A. G. Ideias algébricas explicitadas por estudantes da EJA em espaços nãoformais: o caso do cursinho de Ribeirão Preto. 2011. 108 f. Dissertação (Mestrado em Ensino de Ciências Exatas) - Centro de Ciências Exatas, Universidade Federal de São Carlos, São Carlos, 2011.

CARAÇA, B. J. Conceitos fundamentais da matemática. 2. ed. Lisboa: Gradiva, 1998.

COCHRAN-SMITH, M.; LYTLE, S. L. Dentro/fuera: enseñantes que investigan. Madrid: Akal, 2002.

DINIZ-PEREIRA, J. E.; ZEICHNER, K. M. (Org.). A pesquisa na formação e no trabalho docente. 2. ed. Belo Horizonte: Autêntica, 2011.

FIORENTINI, D.; LORENZATO, S. Investigação em educação matemática. Campinas: Autores Associados, 2006.

GOMES, A. N. Uma proposta de ensino envolvendo geometria fractal para o estudo de semelhança de figuras planas. 2010. 228 f. Dissertação (Mestrado em Ensino de Ciências Exatas) Centro de Ciências Exatas, Universidade Federal de São Carlos, São Carlos, 2010.

INSTITUTO NACIONAL DE ESTUDOS E PESQUISAS EDUCACIONAIS ANÍSIO

TEIXEIRA. Estatísticas dos professores no Brasil. Brasília: INEP, 2003. Disponível em: $<$ http:/ / www.sbfisica.org.br/arquivos/estatisticas_professores_INEP_2003.pdf >. Acesso em: 12 fev. 2013.

LEONTIEV, A. N. Actividad, consciencia, personalidad. La Habana: Editorial Pueblo y Educación, 1983.

MENDES, A. F. Da resolução de quebra-cabeças em sala de aula à aplicabilidade no cotidiano de uma marmoraria: o que os estudantes do $9^{\circ}$ ano do ensino fundamental falam e escrevem sobre o conceito de área. 2012. 159 f. Dissertação (Mestrado em Ensino de Ciências Exatas) - Centro de Ciências Exatas, Universidade Federal de São Carlos, São Carlos, 2012.

MOURA, A. R. L. et al. Movimento conceitual em sala de aula. In: CONFERÊNCIA INTERAMERICANA DE EDUCAÇÃO MATEMÁTICA, 11. 2003, Blumenau. Anais... Blumenau: [s.n.], 2003. v. 1, p. 1-15. 
MOURA, M. O. (Org). A atividade pedagógica na teoria histórico-cultural. São Paulo: Liber, 2010.

NÓVOA, A. Os professores e a sua formação. Lisboa: Dom Quixote, 1992.

PAEZ, G. R. Formação de sentidos e significados matemáticos por meio da leitura da obra $\mathbf{O}$ homem que calculava. 2012. 120 f. Dissertação (Mestrado em Educação) - Centro de Educação e Ciências Humanas, Universidade Federal de São Carlos, São Carlos, 2012.

PERRENOUD, P. Práticas pedagógicas, profissão docente e formação: perspectivas sociológicas. Lisboa: Dom Quixote: Inst. de Inovação Educacional, 1993.

RÊGO, R. M.; RÊGO, R. G. Desenvolvimento e uso de materiais didáticos no ensino de matemática. In: LORENZATO, S. (Org.). O laboratório de ensino de matemática na formação de professores. Campinas: Autores Associados, 2006. p. 39-56.

RIBEIRO, A. C. Formar professores: elementos para uma teoria e prática da formação. Lisboa: Texto Editora, 1993.

SÃO PAULO (Estado). Secretaria de Estado da Educação. Saresp 2007. Disponível em: < http:// saresp.fde.sp.gov.br/2007/subpages/saresp.html >. Acesso em: 18 ago. 2014.

SCHMIDT, M. L. S. Pesquisa participante: alteridade e comunidades interpretativas. Psicologia USP, São Paulo, v. 17, n. 2, p. 11-41, 2006.

SILVA, M. A. Elaborações de estudantes do $7^{\circ}$ ano do ensino fundamental sobre números inteiros e suas operações. 2012. 120 f. Dissertação (Mestrado em Ensino de Ciências Exatas) Centro de Ciências Exatas, Universidade Federal de São Carlos, São Carlos, 2012.

SOUSA, M. C. A percepção de professores atuantes no ensino de matemática nas escolas estaduais da delegacia de ensino de Itu, do movimento matemática moderna e de sua influência no currículo atual. 1999. 184 f. Dissertação (Mestrado em Educação) - Faculdade de Educação, Universidade Estadual de Campinas, Campinas, 1999. Disponível em: <http://www. bibliotecadigital.unicamp.br/document/?code=vtls000188621>. Acesso em: 12 fev. 2013.

VAZQUEZ, C. M. R. O ensino de análise combinatória no ensino médio por meio de atividades orientadoras em uma escola estadual do interior paulista. 2011. 88 f. Dissertação (Mestrado em Ensino de Ciências Exatas) - Centro de Ciências Exatas, Universidade Federal de São Carlos, São Carlos, 2011.

ZEICHNER, K. A formação reflexiva de professores: ideias e práticas. Lisboa: Educa, 1993. 